NBSIR $82-2537$

\title{
An Assessment of Correlations Between Laboratory and Full-Scale Experiments for the FAA Aircraft Fire Safety Program, Part 5: Some Analyses of the Post Crash
}

U.S. DEPARTMENT OF COMMERCE

National Bureau of Standards

National Engineering Laboratory

Center for Fire Research

Washington, DC 20234

and

Building Research Institute

Japan

July 1982

Sponsored by:

"c Department of Transportation

$-$ al Aviation Administration

100 lical Center

.U56 tic City Airport, NJ 08405 
19t 


\section{AN ASSESSMENT OF CORRELATIONS \\ BETWEEN LABORATORY AND \\ FULL-SCALE EXPERIMENTS FOR THE \\ FAA AIRCRAFT FIRE SAFETY PROGRAM, \\ PART 5: SOME ANALYSES OF THE \\ POST CRASH}

James G. Quintiere

U.S. DEPARTMENT OF COMMERCE

National Bureau of Standards

National Engineering Laboratory

Center for Fire Research

Washington, DC 20234

and

Takeyoshi Tanaka (Guest Worker)

Building Research Institute

Japan

July 1982

Sponsored by:

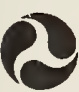

U.S. Department of Transportation

Federal Aviation Administration

Technical Center

Atlantic City Airport, NJ 08405

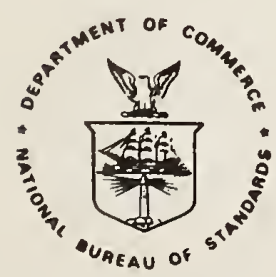

U.S. DEPARTMENT OF COMMERCE, Malcolm Baldrige, Secretary NATIONAL BUREAU OF STANDARDS, Ernest Ambler, Director 



\begin{abstract}
An attempt is made to develop mathematical predictions for various aspects of the dynamics of post crash aircraft fires. The basis of the analysis is the experimental simulation scenario under study by the FAA. The effects of wind are considered as well as the effect of interior and exterior fires. Suggestions are presented for estimating cabin door flow rates from measured teniperatures.
\end{abstract}

Keywords: Doorway flows, mathematical modeling, post crash aircraft fires, wind effects 



\section{TABLE OF CONTENTS}

Page

INTRODUCTION

1

Purpose

1

Background

1

$\begin{array}{lr}\text { ANALYSIS OF WIND EFFECTS } & 1\end{array}$

SIMULATION OF A POST CRASH FIRE SCENARIO 2

FLOW MEASUREMENTS $\quad 4$

$\begin{array}{lr}\text { REFERENCES } & 6\end{array}$

APPENDIX 


\section{LIST OF ILLUSTRATIONS}

Figure

Page

1 Aircraft Cabin Schematic

2 C'abin Temperature Due to Wind and Excernal Fire

3 Frediction of Cabin Temperature for an External Fire Under Wind Conditions

4 Predicted Cabin Temperature Due to External Pool Fire and Cabin Fire (No Wind)

5 Predicted Cabin Fire Induced Flows for $4.5 \mathrm{~m}^{2}$ Pool Fire

6 Predicted Cabin Temperature and Smoke Layer Height for $6.0 \mathrm{~m}^{2}$ Pool Fire and Various Cabin Fires

$7 \quad$ Predicted Cabin Fire Induced Flows for a $6 \mathrm{~m}^{2}$ Pool Fire 


\section{LIST OF TABLES}

Table

1 Cabin Temperature Dependence on Pool Fire and Cabin Fire

A-1

Limits of Integration

A-2 Rate of Air Flow Estimated from Temperature Data

Page

7

$A-2$ 


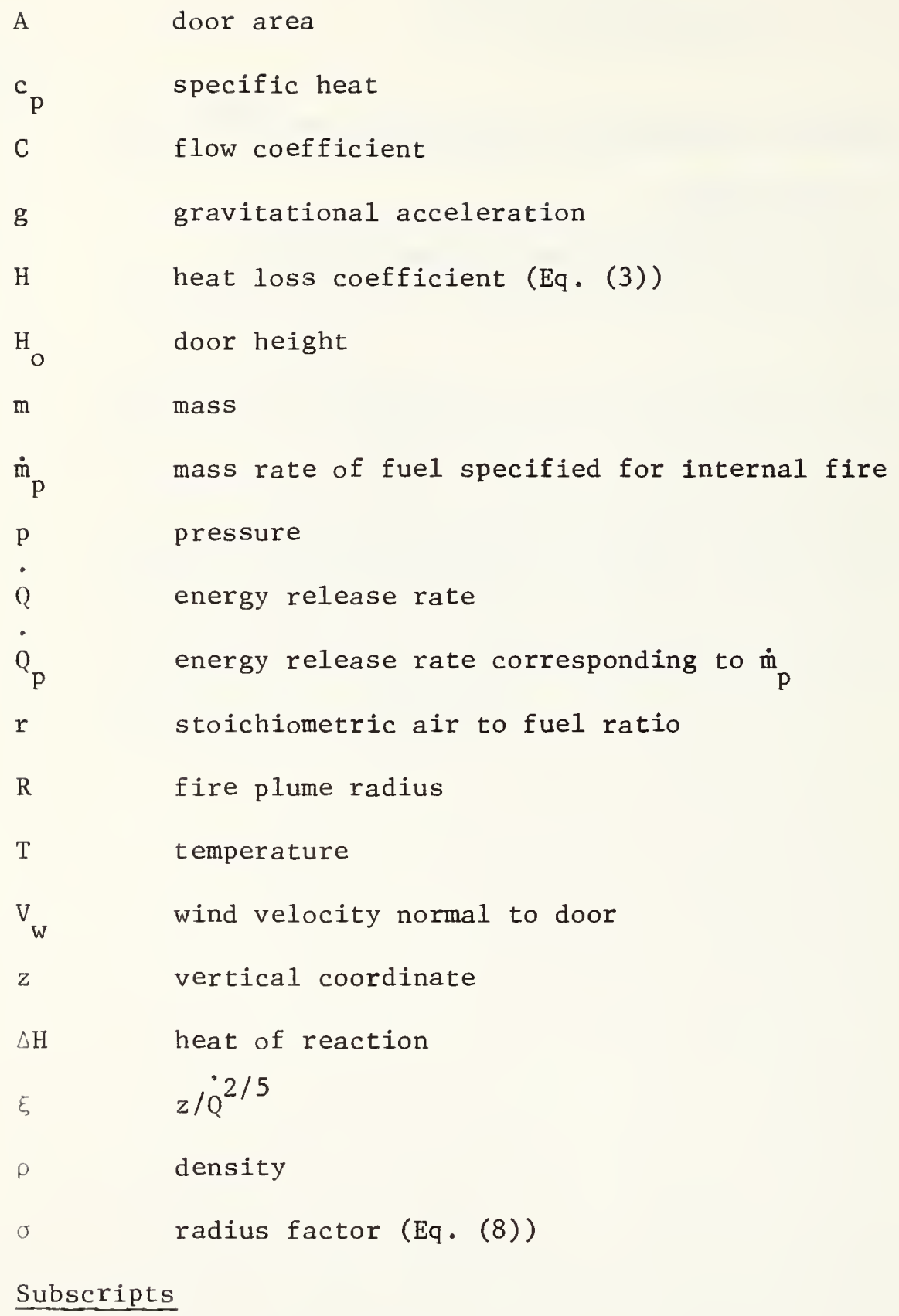

Subscripts

i inflow or inside

f fuel

o ambient or outside 


\section{ACKNOWLEDGEMENT}

This study was sponsored by the Fire Safety Branch of The Federal Aviation Administration Technical Center at Atlantic City, New Jersey. The author gratefully appreciates the advice of Mr. R. Hill, the technical monitor, and also the assistance of Mr. C. Sarkos of the FAA. 



\section{PURPOSE}

The development of correlations between laboratory test methods and ful1scale fire behavior does not only depend on the appropriateness of the laboratory test. The dynamics of the full-scale fire scenario must also be understood, at least in qualitative terms. Part of this insight must come from actual fire simulation experiments. In addition, it is necessary to analyze those data and develop mathematical modeling of at least aspects of the scenario to produce generalized results. Some results of data analysis and modeling will be presented for the wide-body post crash aircraft fire currently under study by the FAA.

\section{BACKGROUND}

Ful1-scale fire studies have been conducted by Brown [1] using a DC7 fuselage and Hill, Johnson and Sarkos [2] using a C133 fuselage. These studies addressed the post crash fire scenario by considering a large external fuel pool fire adjacent to an open cabin door. Various temperature, heat and gas data were collected, and the effect of external ambient wind conditions, pool size and door openings were examined. Eklund and Wright [3] did a small scale study to examine the effect of door location relative to the pool fire. Stuart [4] presented an analysis based on Bernoulli's equation, for computing the air flow rate through cabin door openings due to wind effects. More recently Emmons [5] presented a more complete mathematical analysis of the ingestion of fire gases into the cabin door opening. He proposed methods to include the entrainment effect of the external fire, the capture of pool fire gases due to plume expansion, and the flow due to pressure differences inherent in the wind flow. The "capture" phenomenon is very complex and, in fact, manifests itself as a pulsation of flames at the cabin door [6]. Modeling this effect may require further attention. Nevertheless an understanding of the processes can be developed through these mathematical modeling concepts, and these concepts have been used in the analyses which follow.

\section{ANALYSIS OF WIND EFFECTS}

The experimental study by Hill et al. [2] will be used as a source of data and a basis for analysis. A schematic of that experiment is shown in Figure 1 in a somewhat distorted form. For ease in illustration the doors are shown on the ends, the cabin is considered rectangular in cross-section, and the wind is directed normal to the fire door while the exit door experiences ambient pressure since it was baffled from the wind. The objective will be to construct some appropriate models and perform some sample computations to illustrate the dynamics of the transport of heat and mass in the aircraft as a function of wind conditions, and external and internal fire sizes for this port crash scenario.

The first approach taken was to attempt a correlation for the cabin temperature data (at time $t=240 \mathrm{~s}$ ) given in Figure 16-18 of reference [2]. These data represent the cabin upper gas temperature due to various wind conditions and various external pool fire dimensions. Since the external fuel fire has large flame dimensions relative to the doorway, it was assumed that the rate of energy release in the cabin is controlled by the rate of air flow into the cabin through the fire door. . This flow is actually composed of fuel, air and products and is considered to be fuel rich such that sufficient fuel is available to cause all the air to react. 
Thus, the rate of air flow in through the cabin doorway controls the rate of energy release. For simplicity this flow is taken as a stoichiometric mixture with $r$ as the air fuel ratio. Hence the inflow rate

$$
\dot{\mathrm{m}}_{\mathrm{i}}=\dot{\mathrm{m}}_{\mathrm{f}}(1+\mathrm{r})
$$

where $\dot{\mathrm{m}}_{\mathrm{f}}$ is the fuel burning rate of the gases entering the cabin due to wind effects. This flow is driven through the cabin door primarily by the stagnation pressure resulting from the normal wind velocity $\left(V_{W}\right)$. From Bernoulli's equation and orifice flow theory (neglecting the effect of ${ }^{\mathrm{W}}$ the exit opening)

$$
\dot{\mathrm{m}}_{\mathrm{i}}=\mathrm{C} \rho_{\mathrm{o}} \mathrm{V}_{\mathrm{w}} \mathrm{A}
$$

where $C$ is a flow coefficient,

$\rho_{0}$ is the ambient density,

and $\mathrm{A}^{\mathrm{O}}$ is the opening area of the door.

An energy balance was performed for a control volume between the fire door and the temperature data station (Figure 1). The wind conditions were assumed to dominate so that only unidirectional flow occurred (fire to exit door).

$$
\dot{\mathrm{m}}_{i} \mathrm{c}_{\mathrm{p}}\left(\mathrm{T}-\mathrm{T}_{\mathrm{o}}\right)=\dot{\mathrm{m}}_{\mathrm{f}} \Delta \mathrm{H}-\mathrm{H}\left(\mathrm{T}-\mathrm{T}_{\mathrm{o}}\right)
$$

The enthalpy flow rate equals the energy release in the cabin minus the heat loss where

$\Delta \mathrm{H}$ is the heat of combustion of the pool fire fuel,

$\mathrm{H}$ is an effective wall heat loss coefficient,

$\mathrm{T}$ is the average temperature in the cabin,

and

$\mathrm{T}$ is ambient (initial) temperature,

$\mathrm{c}_{\mathrm{p}}^{\mathrm{o}}$ is the specific heat.

Combining Eqns (1)-(3) yields

$$
\mathrm{T}-\mathrm{T}_{\mathrm{o}}=\frac{\Delta \mathrm{H}}{\mathrm{c}_{\mathrm{p}}(1+\mathrm{r})} \quad\left(1+\frac{\mathrm{H}}{\mathrm{c}_{\mathrm{p}} \mathrm{C} \rho_{\mathrm{o}} \mathrm{AV}_{\mathrm{w}}}\right)^{-1}
$$

If $\mathrm{H}$ is large, implying a large surface heat transfer area (not unreasonable in the $\mathrm{C} 133$ experiments), then $\mathrm{T}-\mathrm{T}$ should be directly proportional to $\mathrm{V}$. The data were examined on that basis and a plot of the results was shown ${ }^{\mathrm{W}}$ in Figure 2. It should be noted that the temperature station is $3 \mathrm{~m}$ from the door and $1.7 \mathrm{~m}$ from the floor, and the time-averaged wind velocity normal to the door is based on measurements taken by cup and vane type sensors located at the front and rear of the fuselage. Except for perhaps two data points (one in which the thermocouple was probably in the flames and therefore not representative of an average gas temperature), the results are encouraging. They suggest that Eq. (4) could serve as a guide in estimating the effect of the external fire and wind on the cabin temperature rise.

\section{SIMULATION OF A POST CRASH FIRE SCENARIO}

Since this approach of correlating the wind effects on cabin temperature was relatively successful it encouraged further analysis. Tanaka's existing model [6], considers mass, energy and specie conservation for a homogeneous combustion product zone (upper layer) and an air zone (lower layer). Various vertical openings can be considered in the computation and a fire source plume is specified in one compartment. The current application considers a single room cabin with two door openings. In addition the post crash fire analysis was addressed by introducing the following modifications: 
(1) Flow into the cabin at the fire door was assumed to react in stoichiometric proportion (i.e. burning is alr controlled) such that the rate of energy added to the cabin from the pool fire due to pressure differences is

$$
\dot{\mathrm{Q}}_{1}=\frac{\dot{\mathrm{m}}_{i} \Delta \mathrm{H}}{(\mathrm{r}+1)} \text {. }
$$

The flow rate $\dot{\mathrm{m}}_{1}$ and the energy release rate $\dot{Q}_{1}$ enter the hot layer of the cabin compartment in Tanaka's mode1 [6].

(2) Flow at each door is governed by the existing pressure differences. The fire door is affected by pool fire entrainment and wind if present. The entralnment effect is negative causing flow out. The exit door has normal ambient pressure $\left(p_{\infty}\right)$ imposed outside the cabin. The external pressure imposed at the fire door 1 s given by superposition of wind and pool fire effects:

$$
\mathrm{p}=\mathrm{p}_{\infty}+\frac{1}{2} \rho_{0} \mathrm{~V}_{\mathrm{w}}^{2}-\frac{1}{8 \pi^{2} \rho_{0} \mathrm{R}^{2}}\left(\frac{\mathrm{d} \dot{\mathrm{m}}}{\mathrm{dz}}\right)^{2}
$$

$R$ is the plume radius, $z$ is the height and $\dot{m}$ is the plume flow rate. The last term in Eq. (6) results from an application of Bernoulli's equation to a streamline starting from rest and extending to the fire plume. McCaffrey's [7] entrainment model was used where rate of entrainment,

$\dot{\mathrm{m}}=\dot{\mathrm{o}}_{\mathrm{p}} \times\left\{\begin{array}{l}0.053 \xi^{1.3}, \\ 0.063 \xi^{5 / 3}, \xi>0.2 \\ 0.2\end{array}\right.$

where $\xi=z / \dot{\mathrm{Q}}_{\mathrm{p}}^{2 / 5}$ and $\dot{\mathrm{m}}(\mathrm{kg} / \mathrm{s}), \dot{\mathrm{Q}}(\mathrm{kW}), \mathrm{z}(\mathrm{m})$.

For the external pool fire it follows that $\xi<0.2$ and

$$
\frac{\mathrm{d} \dot{\mathrm{m}}}{\mathrm{dz}}=0.137 \dot{\mathrm{Q}}_{\mathrm{p}}^{0.48} \mathrm{z}^{0.3}
$$

and $R=\sigma 1 n m, m=10 ., \sigma=0.128 z+0.0062 \dot{Q}^{2 / 5}$ with $\dot{Q}_{p}(k c a l / s)$.

(3) Two cases were computed.

Case a. Wind is considered and a net heat addition due to the "capture" or pulsating flame phenomenon is specified as a fixed rate of fuel ( $\dot{\mathrm{m}}_{\mathrm{p}}$ ) available at the fire door. A stoichiometric amount of air is also added. A $4 \times 6 \mathrm{ft}\left(2.16 \mathrm{~m}^{2}\right)$ pool fire was used.

Case b. An internal cabin fire is specified ( $\dot{\mathrm{m}}_{\vec{p}}$ ) which would simulate the ignition of cabin furnishings. The effect $b_{f}$ fire location is not accounted for by this model. No wind or flame pulsation effects were considered, although they could in principle be included. Both $6 \times 8 \mathrm{ft}\left(4.5 \mathrm{~m}^{2}\right)$ and $8 \times 8 \mathrm{ft}\left(5.0 \mathrm{~m}^{2}\right)$ pool fires were used. The following property values and data were used for the cabin geometry in Figure 1. 
Kerosene fuel: $\quad r=15,30$

$\Delta \mathrm{H}=42 \mathrm{~kJ} / \mathrm{g}$

burning rate $=0.064 \mathrm{~kg} / \mathrm{m}^{2}-\mathrm{s}$

Cabin interior: conductivity $=1.2 \times 10^{-4} \mathrm{~kW} / \mathrm{m}-\mathrm{K}$

specific heat $=1.05 \mathrm{~kJ} / \mathrm{kg}-\mathrm{K}$

density $=500 \cdot \mathrm{kg} / \mathrm{m}^{3}$

thickness $=10 \mathrm{~cm}$

emissivity $=0.8$

Although these data may not match the full-scale conditions perfectly, the fuel estimates are felt to be reasonable and the wall data should not have a strong influence on the flow results.

The results for Case a are shown in Figure 3. They are in qualitative agreement with the data of Hill et al. [2], and could be adjusted into quantitative agreement by selecting "best values" for the parameters $r$ and $\dot{m}$. Uncertainties in $r$ relate to lack of a mixing rate model for fuel and $\mathrm{aP} r$, and in $\dot{\mathrm{m}}$ due to lack of a quantitative understanding of flame pulsation in the doorway. This analysis, however, does provide a framework for more accurate modeling.

The results for Case $\mathrm{b}$ are displayed in Figures 4-7. Two external pool fires are considered $6 \times 8 \mathrm{ft}\left(4.5 \mathrm{~m}^{2}\right)$ and $8 \times 8 \mathrm{ft}\left(6.0 \mathrm{~m}^{2}\right)$ and the internal fire is varied from 10 to $70 \mathrm{~g} / \mathrm{s}$ with $\Delta \mathrm{H}=42 \mathrm{~kJ} / \mathrm{g}$. Both fires are considered to begin impulsively at the same time. A competition exists between the internal and external fires for "air" flow through the fire door. For a small internal fire, flow is completely from the cabin at the fire door as the computed results show. The curves labeled "air" and "smoke" in Figures 4 and 6 are the rates of flow from (or to) the cold cabin air layer and from the hot upper cabin layer, respectively. The term "air" is used loosely since it could pertain to pool fire gases. When "air" flows to the cabin through the fire door it reacts in this model. In the modified Tanaka model this flow and release of heat is abscrbed into hot cabin upper layer. The conditions which cause these pool fire gases to enter the cabin are shown to depend on internal fire size and time. In fact the entering of a substantial flow of pool fire gases into the cabin is a critical event. Table 1 summarizes the results of this critical flow reversal event. For a $4.5 \mathrm{~m}^{2}$ external pool fire, flames will enter the cabin for an internal cabin fire of $2520 \mathrm{~kW}$ at $70 \mathrm{~s}$. For the larger pool fire $\left(6.0 \mathrm{~m}^{2}\right)$, this occurs for a $2940 \mathrm{~kW}$ cabin fire at $90 \mathrm{~s}$. These cabin fire sizes may represent at least fire involvement of several seats, but obviously the development of the fire spread on the seats is not accounted for in these calculations. Nevertheless these results provide insight on the dynamics of the post crash fire and a framework for developing correlations based on cabin material performance.

\section{FLOW MEASUREMENTS}

It would be useful to establish the credibility of these calculations through comparison with experimental results. An essential experimental component would be the determination of the doorway flow rates. This would be very difficult to achieve at the fire door because of flow disturbances due to the pool fire, but much more easily done at the exit door. A basis for determining this flow rate has been established by Steckler et a1. [8] and utilizes temperature measurements alone. A discussion of this approach is presented in the Appendix. 
It should be possible to utilize this technique in the FAA post crash fire experimental facility. The establishment of confidence in this model would lead to the prospect of considering a more realistic fire spread scenario. Such an analysis would be desirable in developing correlations between performance of materials in the post crash experiments and test method data. It is clear, however, from these calculations and observations of the full-scale tests that only some fraction of the energy, smoke, and combustion products from the interior cabin fire is flowing out of the cabin at the fire door. Also when the internal fire becomes large enough, more significant quantities of the pool fire gases are drawn into the cabin. Any correlation strategy, assessment of human tolerance levels in the cabin or egress potential at the exit door needs to account for these fire dynamic characteristics. 


\section{REFERENCES}

1. Brown, L. J. (Jr), "Cabin Hazards from a Large External Fuel Fire Adjacent to an Aircraft Fuselage", Federal Aviation Administration Report No. FAA-RD-79-65, (August 1979).

2. Hil1, R. G., Johnson, G. R., and Sarkos, C. P., "Postcrash Fuel Fire Hazard Measurements in a Wide-Body Aircraft Cabin", Federal Aviation Administration Report No. FAA-NA-79-42, (Dec. 1979).

3. Eklund, T. I., and Wright, J. A., "Fuel Fire Hazard Penetration into a Mode1 Fuselage as a Function of Circumferential Door Location and Fuel Bed Height", Federal Aviation Administration Report No. FAA-NA-80-9, (May 1980).

4. Stuart, J. W., "Fuselage Ventilation Due to Wind Flow About a Postcrash Aircraft", Jet Propulsion Laboratory Publication 80-36, (June 1980).

5. Emmons, H. W., "The Ingestion of Flames and Fire Gases into a Hoie in an Aircraft Cabin for Small Tilt Angles and Low Wind Speeds", Harvard University, Home Fire Project Technical Report No. 49, (Oct. 1981).

6. Tanaka, T., "A Model on Fire Spread in Small Scale Buildings, 2nd Report", Building Research Institute (Japan) Research Paper No. 84, (March 1980).

7. McCaffrey, B. J. and Cox, G., "Entrainment and Heat Flux of Buoyant Diffusion Flames", National Bureau of Standards Report, NBSIR (to be published).

8. Steckler, K., Quintiere, J., and Rinkinen, W., "Flow Induced by Fire in a Compartment", National Bureau of Standards (to be published).

9. Prahl, J., and Emmons, H. W., Combustion and Flame, Vo1. 25, No. 3, (Dec. 1975) p. 369. 


\section{TABLE 1}

CABIN TEMPERATURE DEPENDENCE ON POOL FIRE AND CABIN FIRE

\begin{tabular}{|c|c|c|c|c|}
\hline $\begin{array}{l}\text { Pool fire } \\
\text { Area } 2 \\
\qquad\left(m^{2}\right)\end{array}$ & $\begin{array}{c}\text { Cabin fire } \\
\stackrel{Q^{\prime}}{(k W)}\end{array}$ & $\begin{array}{l}\text { Pool fire } \\
\text { enters cabin } \\
\text { (s) }\end{array}$ & $\begin{array}{l}\text { Corresponding } \\
\text { cabin temperature } \\
\qquad\left({ }^{\circ} \mathrm{C}\right)\end{array}$ & $\begin{array}{c}\text { Cabin temperature } \\
\text { at } 240 \mathrm{~s} \\
\left({ }^{\circ} \mathrm{C}\right)\end{array}$ \\
\hline 4.5 & 2100 & $\infty$ & - & 390 \\
\hline 4.5 & 2520 & 70 & 390 & 480 \\
\hline 4.5 & 2940 & 85 & 400 & 540 \\
\hline 6.0 & 420 & $\infty$ & - & 150 \\
\hline 6.0 & 840 & $\infty$ & - & 230 \\
\hline 6.0 & 1260 & $\infty$ & - & 290 \\
\hline 6.0 & 1680 & $\omega$ & - & 350 \\
\hline 6.0 & $2 i 00$ & $\infty$ & - & 390 \\
\hline 6.0 & 2520 & $\infty$ & - & 440 \\
\hline 6.0 & 2940 & 90 & 420 & 540 \\
\hline
\end{tabular}



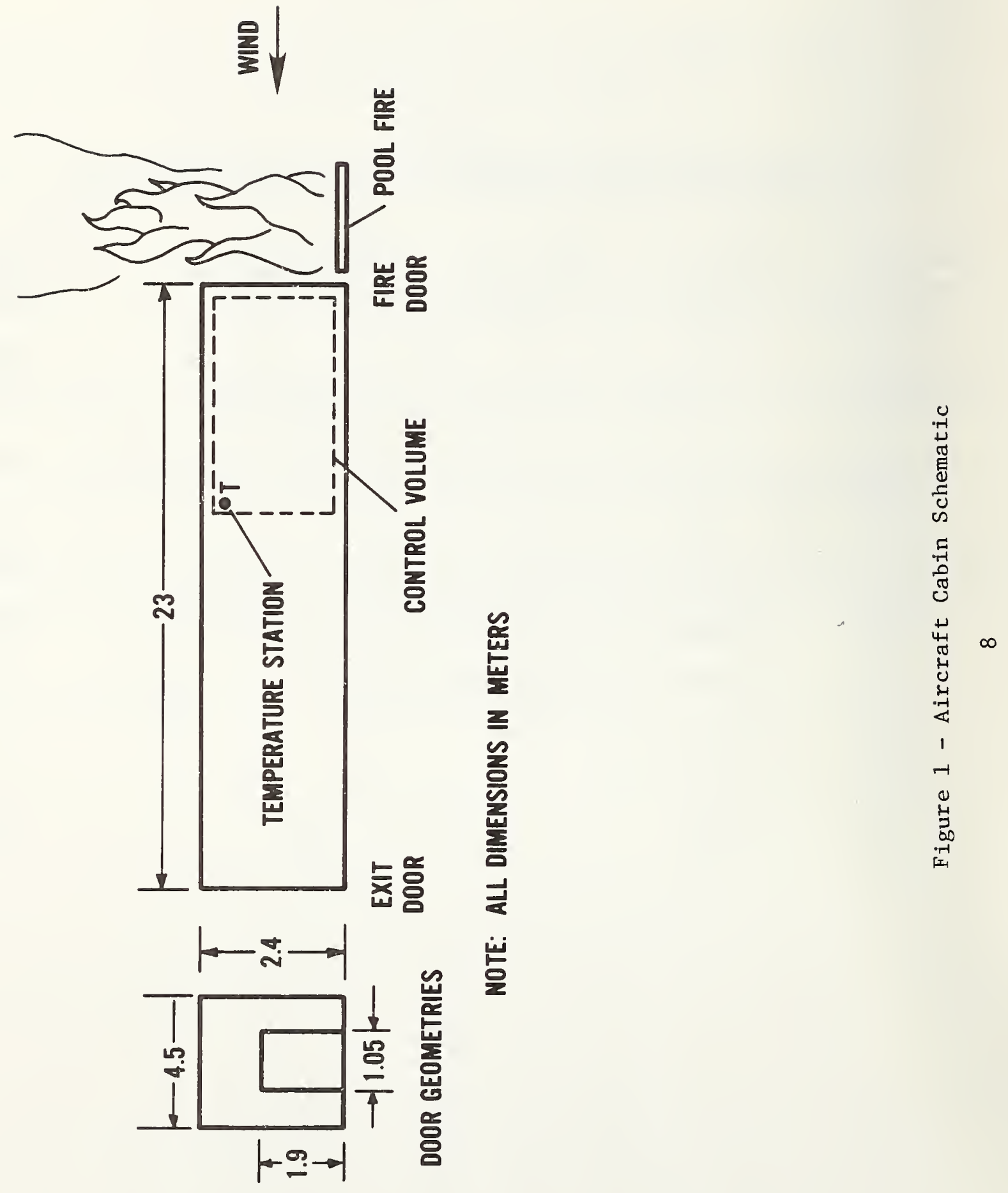


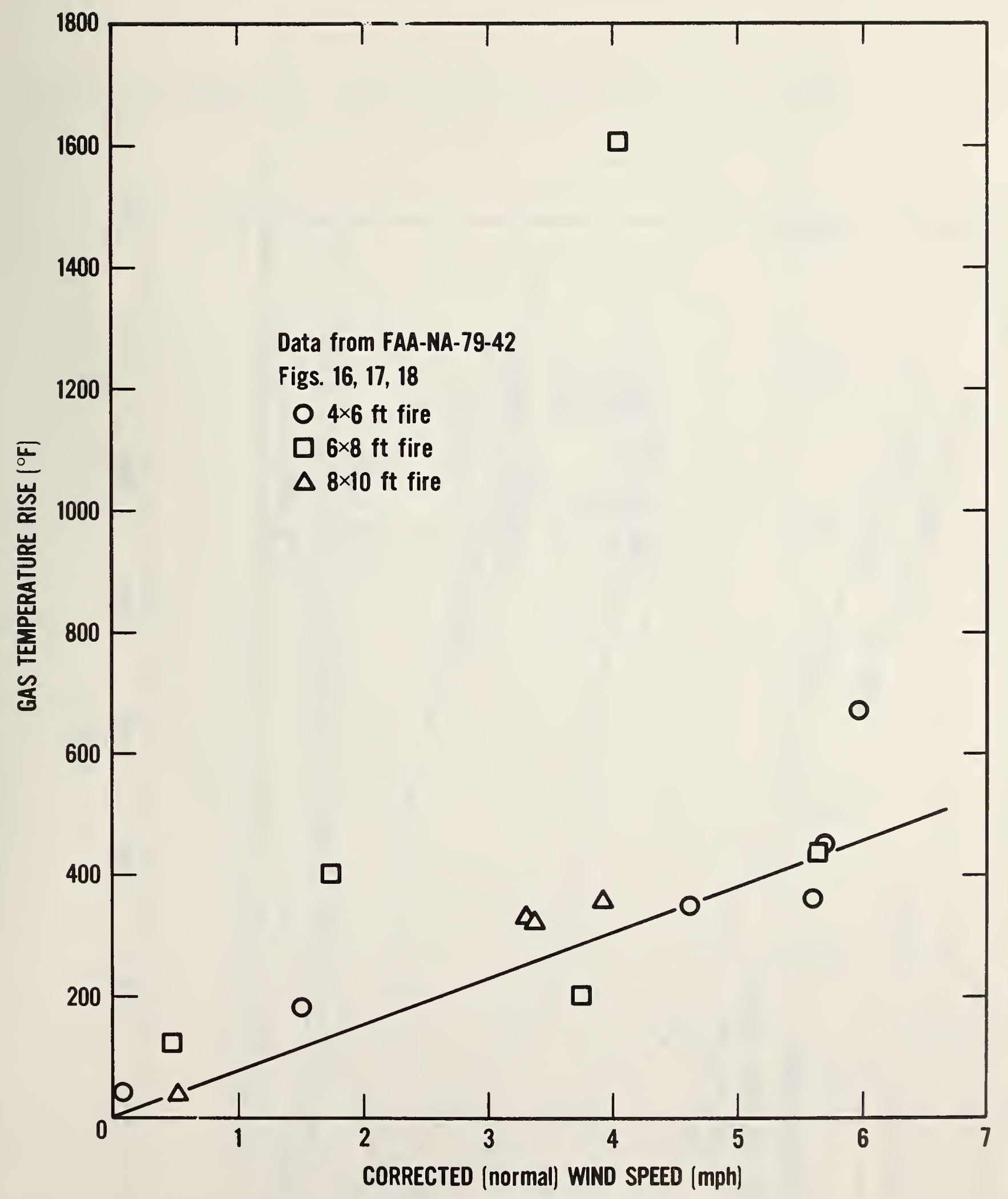

Figure 2 - Cabin Temperature Due to Wind and External Fire 


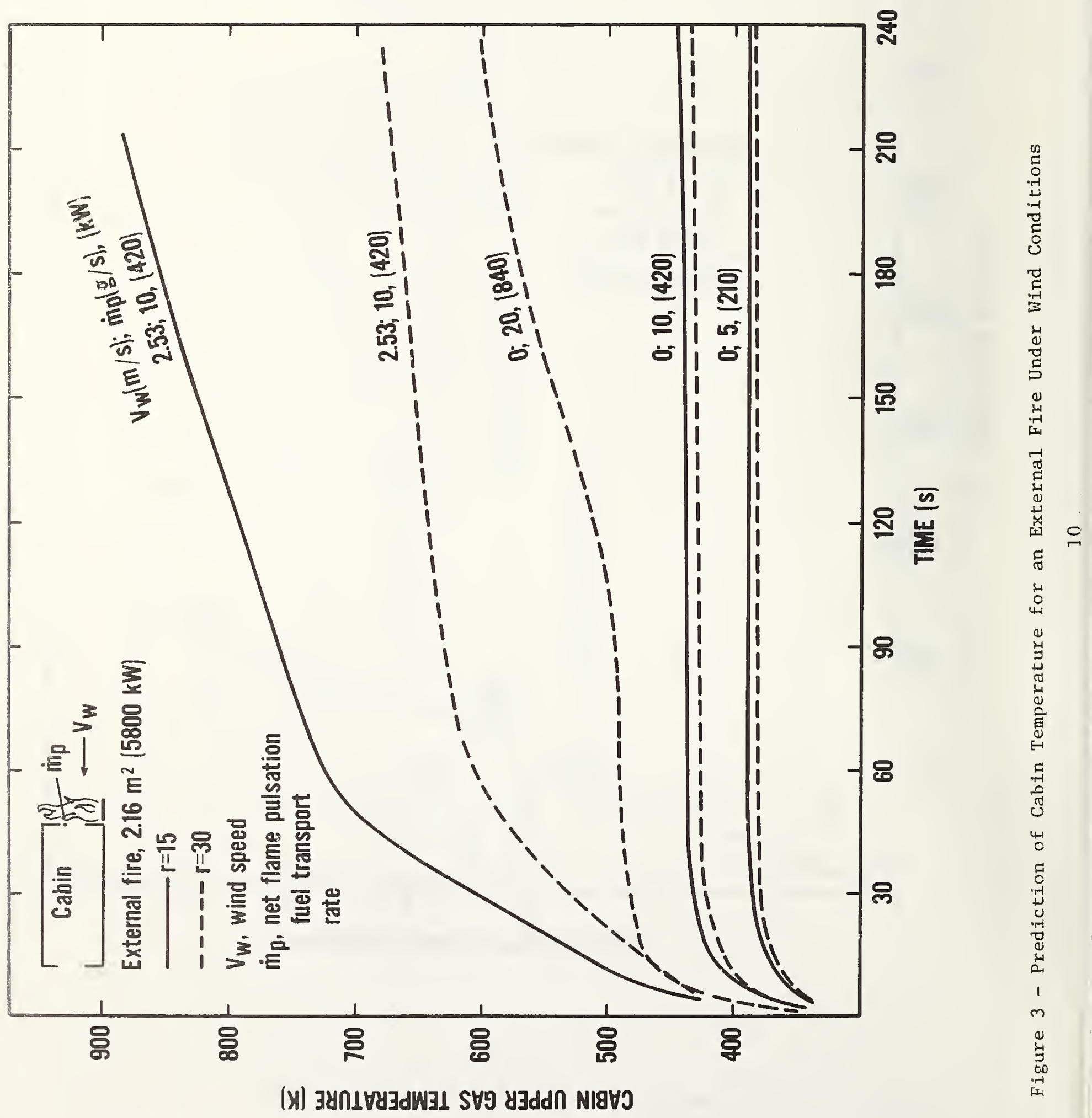




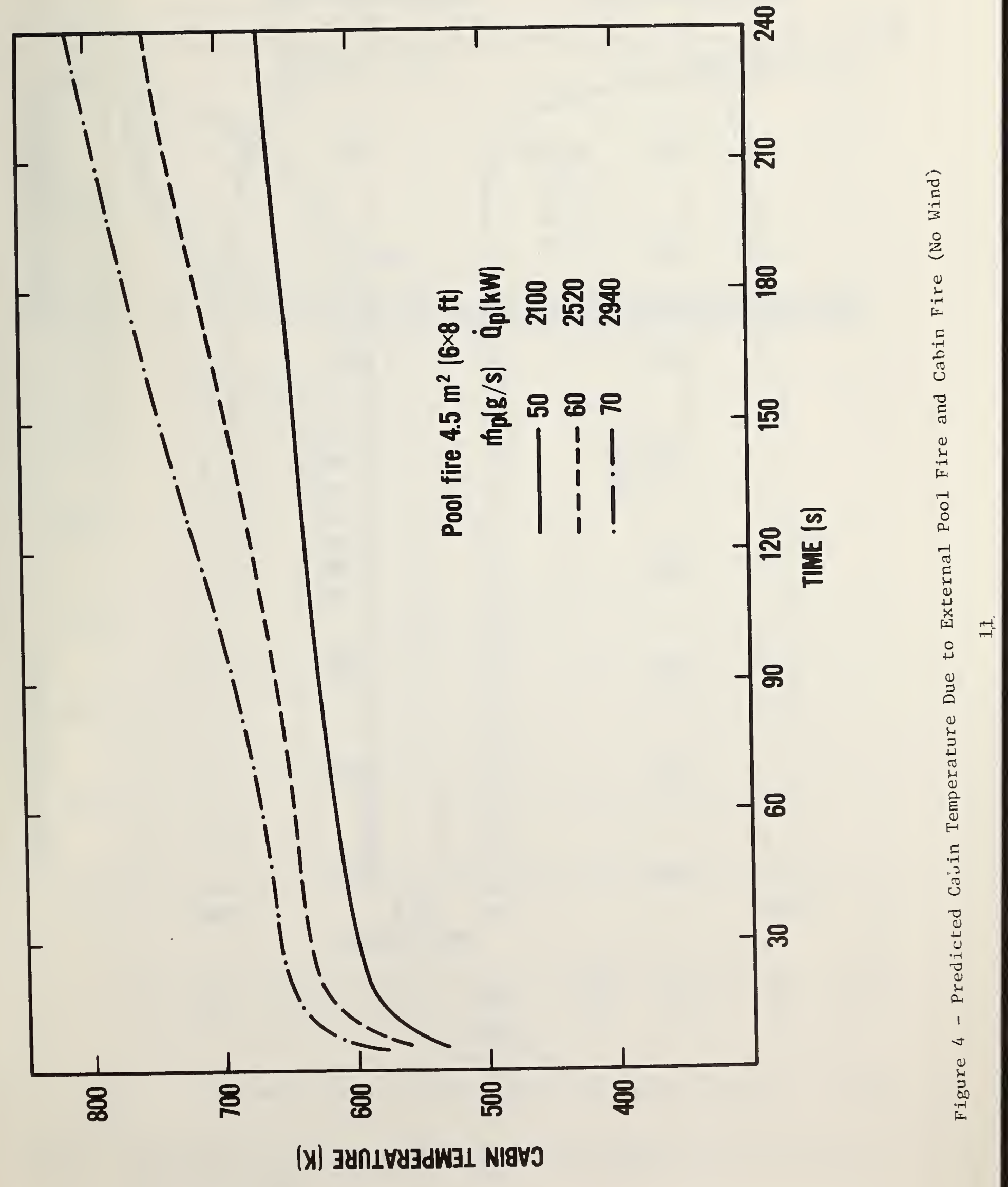



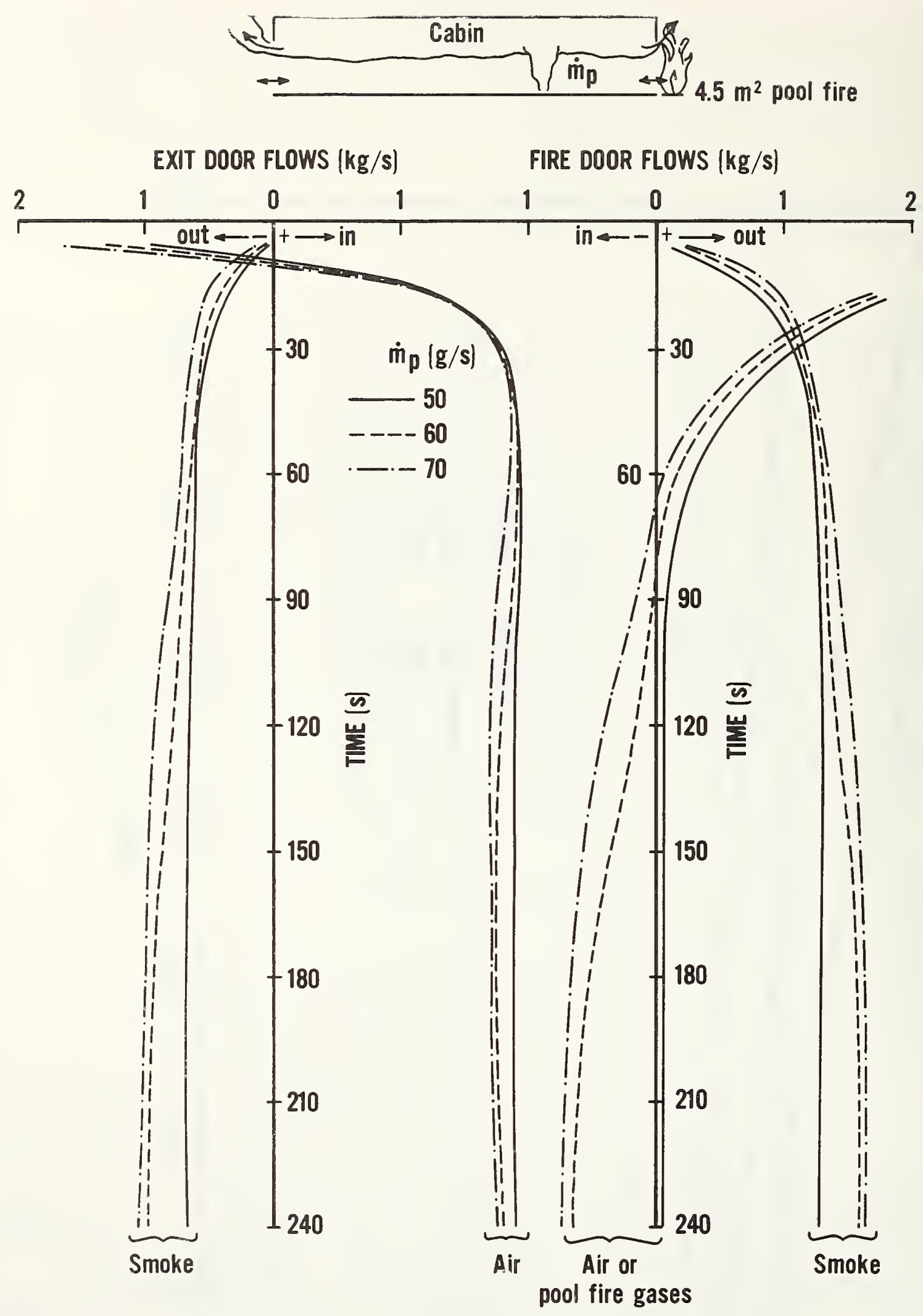

Figure 5 - Predicted Cabin fire Induced Flows for $4.5 \mathrm{~m}^{2}$ Pool Fire 


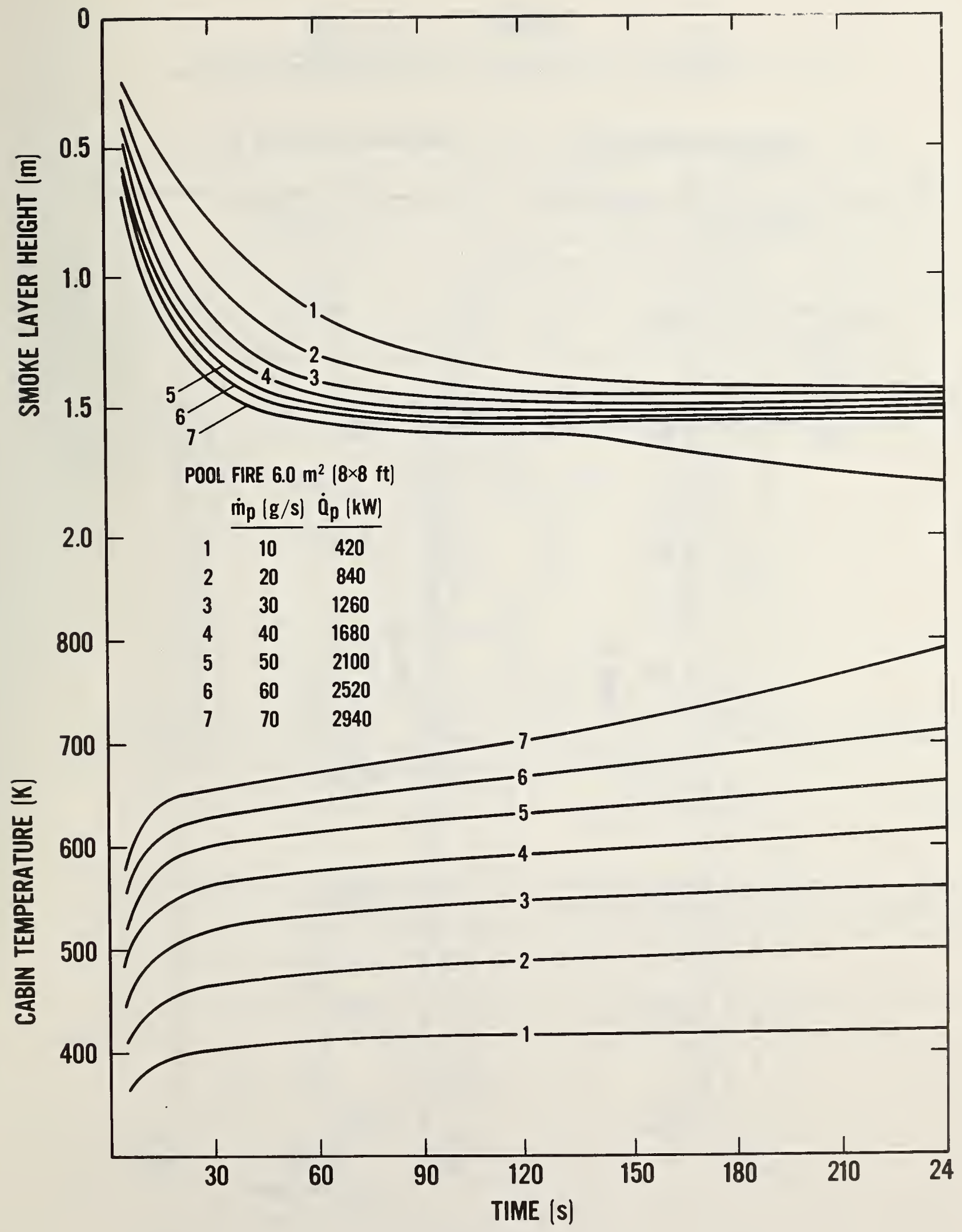

Figure 6 - Predicted Cabin Temperature and Smoke Layer Height for $6.0^{2}$ Pool Fire and Various Cabin Fires 

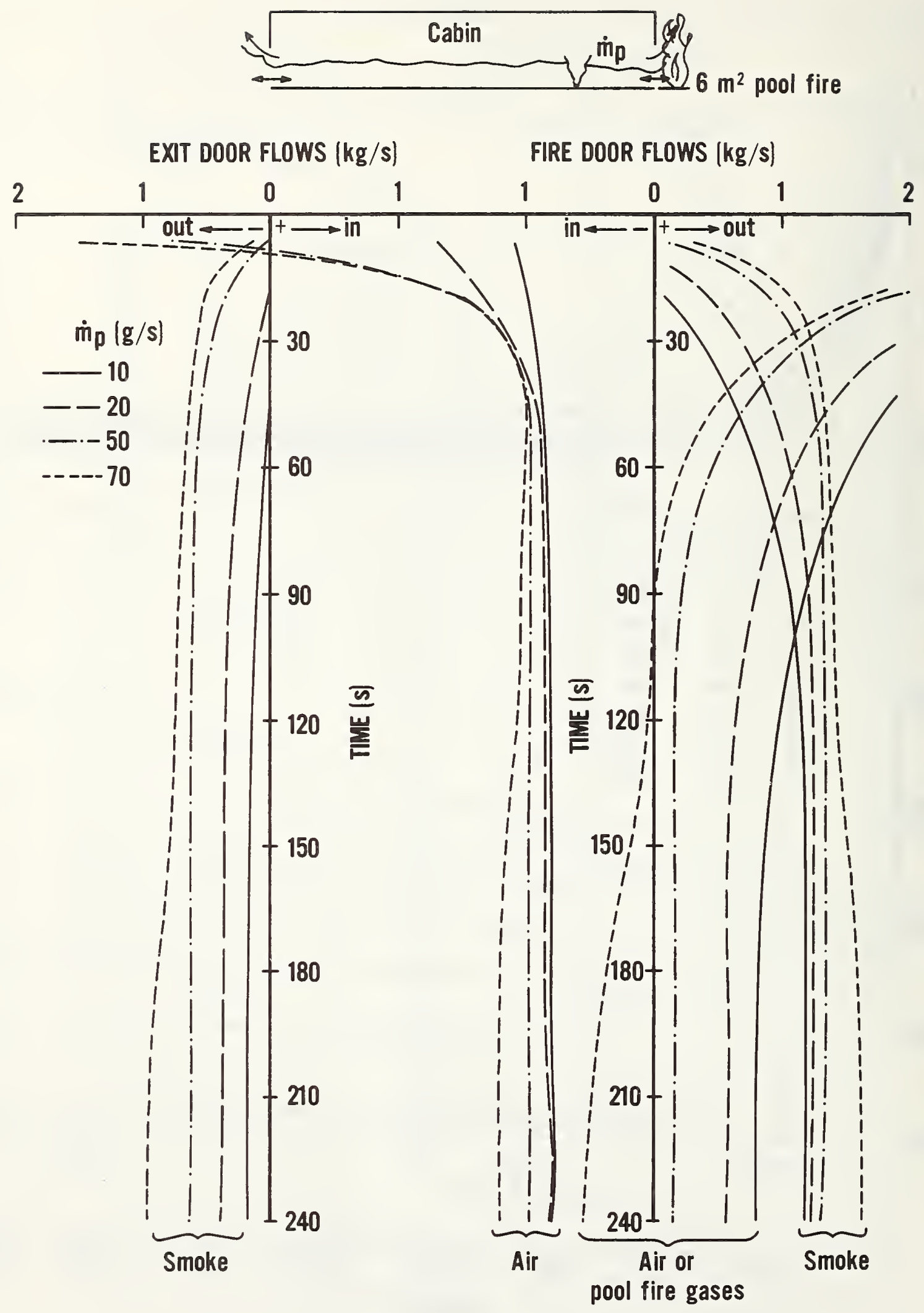

Figure 7 - Predicted Cabin Fire Induced Flows for a $6 \mathrm{~m}^{2}$ Pool Fire 
It has been shown, for room openings of conventional sizes, that a hydraulics flow model is appropriate for estimating the flow rates [9]. The study by Prahl and Emmons [9] and the recent work of Steckler [8] show that the required flow coefficient for this calculation is 0.7 to within about 15 percent. Moreover, the pressure distribution in a compartment subject to a fire is governed principally by hydrostatics. Therefore the flow across an opening may be determined from temperature data alone and more generally with the additional measurement of a single pressure difference across the opening. This will be described and illustrated below. A vertical opening will be considered but a similar procedure could be applied to a horizontal opening.

Figure A-1 illustrates a vertical opening with known temperature distribution on each side - referred to as "inside" (i) and "outside" (o) for labeling purposes.

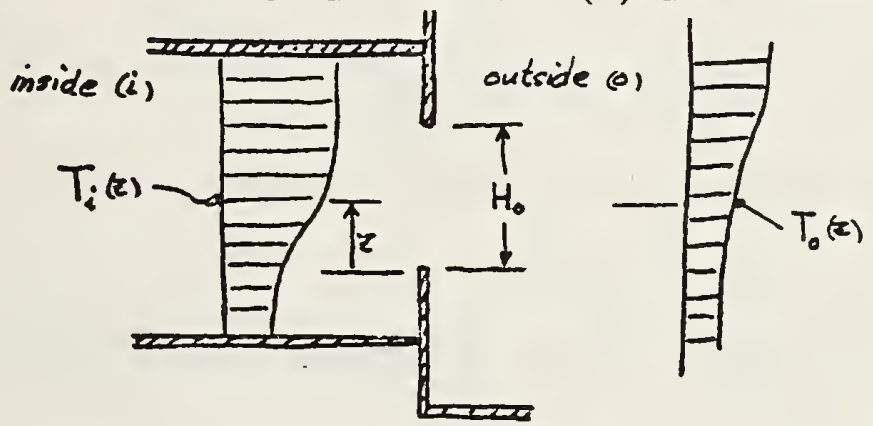

Figure A-I. Conditions at an Opening

The pressure drives the flow across the opening (except for openings that are "large" relative to the enclosure surface area), and is given by hydrostatics. The pressure drop across the opening for any height $z$ is

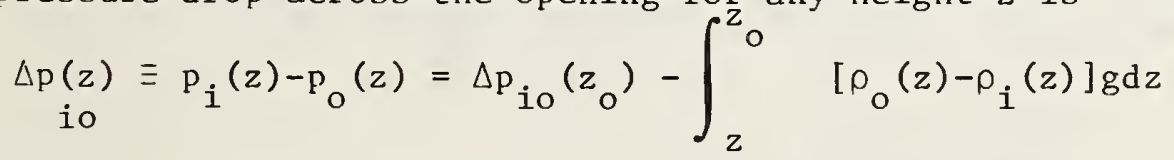

A reference pressure difference $\Delta p_{i o}\left(z_{0}\right)$ must be measured in general. However if the position of flow reversal (1.e. the neutral plane height $N$ ) is known, then $\Delta \mathrm{p}_{\text {io }}(\mathrm{N})=0$ is the reference pressure. In some cases, $\mathrm{N}$ can be determined from temperature measurements in the plane of the opening.

The rate of mass flow, with flow from $i$ to o taken as positive in sign, is given as

$$
\dot{\mathrm{m}}_{\text {io }}=\mathrm{CW} \int_{\mathrm{z}_{1}}^{\mathrm{z}_{2}} \rho_{\mathrm{d}}(z) \mathrm{Vdz}
$$

where $W$ is the width of the opening $\mathrm{C}^{\mathrm{O}}$ is 0.7

$\rho_{d}$ is the density at the opening (and may be approximated as $\rho_{i}$ or $\rho_{0}^{d}$ at the corresponding height $z$ )

The limits of integration depend of the sign of $\Delta p_{10}$. 
TABLE A-1 LIMITS OF INTEGRATION

\begin{tabular}{|c|c|c|c|}
\hline & $\begin{array}{l}\Delta \mathrm{p}_{\text {io }}>0 \\
\text { for all } \mathrm{z}\end{array}$ & $\begin{array}{l}\Delta \mathrm{p}_{\text {io }}>0 \text { and }<0 \\
\left(\Delta \mathrm{p}_{\text {io }}=0 \text { at } z=\mathrm{N}\right)\end{array}$ & $\begin{array}{l}\Delta p_{\text {io }}<0 \\
\text { for ail } z\end{array}$ \\
\hline${ }_{2} 1$ & 0 & $\mathrm{~N}$ & 0 \\
\hline $\mathrm{z}_{2}$ & $\mathrm{H}_{0}$ & $\mathrm{H}$ & $\mathrm{H}_{\mathrm{O}}$ \\
\hline $\overrightarrow{\mathrm{m}}_{\mathrm{io}}$ & + & + & - \\
\hline
\end{tabular}

These limits for usual cases are given in Table A-1. The natural ventilation case for a single opening has a change in sign for $\Delta p_{\text {ind }}$ and therefore flow is both in ( $(-)$ and out ( () . The other conditions would apply for cases of multiple openings, wind or forced ventilation. The idealized velocity is given by Bernoulli's equation assuming the streamline density is the value at the opening $\left(\rho_{d}\right)$ :

$$
V(z)=\operatorname{sgn}\left(\Delta p_{i o}\right) \frac{2\left|\Delta p_{i o}(z)\right|}{\rho_{d}(z)} 1 / 2
$$

The final equation needed is an equation of state which is

$$
\rho \mathrm{T}=\rho_{\infty} \mathrm{T}_{\infty}=\text { constant. }
$$

This is applicable to fire related situations since changes in absolute pressure level are small.

The case of natural ventilation for a single opening in which the fuel supply rate is small relative to flow rate through the opening is a typical room fire condition. If the outside temperature is uniform, $T_{0}=T_{\infty}$, and the inside temperature is approximated by a step-function

$$
\mathrm{T}_{i}=\left\{\begin{array}{l}
\mathrm{T}_{\mathrm{u}}, z>\mathrm{N} \\
\mathrm{T}_{\ell}=\mathrm{T}_{\infty}, z<\mathrm{N}
\end{array}\right.
$$

then the flow rate out and air flow rate into the room is given as

$$
\dot{\mathrm{m}}_{\mathrm{a}}=\frac{2}{3} \mathrm{C} \mathrm{w}_{\mathrm{O}} \rho_{\infty}\left[2 \mathrm{~g}\left(\frac{\mathrm{T}_{\infty}}{\mathrm{T}_{\mathrm{u}}}\right)\left(1-\frac{\mathrm{T}_{\infty}}{\mathrm{T}_{\mathrm{u}}}\right)\right]^{1 / 2} \quad\left(\mathrm{H}_{\mathrm{o}}-\mathrm{N}\right)^{3 / 2}
$$

(It was also assumed that $\rho_{\mathrm{d}}=\rho_{\mathrm{i}}=\rho_{\infty} \mathrm{T}_{\infty} / \mathrm{T}_{\mathrm{u}}$ for $\mathrm{z}>\mathrm{N}_{\text {.) }}$

A comparison of the results of this calculation, based on experimentally determined values of $\mathrm{N}$ and $\mathrm{T}$, with the measured results of Steckler [5] are shown in Table A-2. The quality of the measured results was assessed by achieving a mass balance generally within 5 per cent or less. The derivation of the estimated results from the measured values are well within \pm 10 per cent. This is far superior to attempting to measure the flow rate by $\bar{a}$ limited number of velocity probes in a centered vertical array positioned in a room opening. 


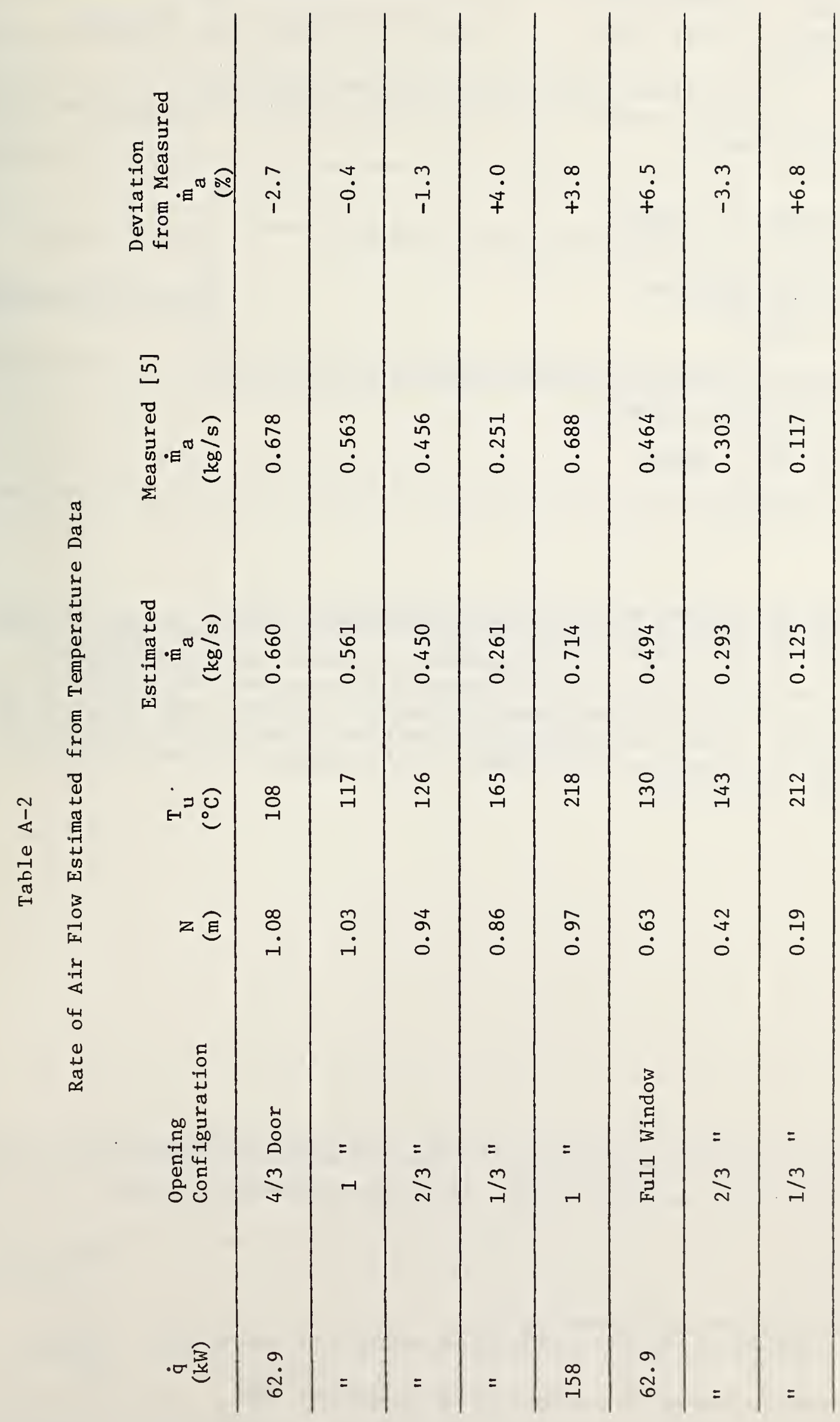




U.S. DEPT. OF COMM.
BIBLIOGRAPHIC DATA
SHEET (See instructions)

1. PUBLICATION OR
REPORT NO.
NBSIR 82- 2537

4. TITLE AND SUBTITLE

An Assessment of Correlations Between Laboratory and Full-Scale Experiments for the FAA Aircraft Fire Safety Program, Part 5: Some Analyses of the Post Crash Fire Scenario

\section{AUTHOR(S)}

James G. Quintiere \& T. Tanaka

6. PERFORMING ORGANIZATION (If joint or other than NBS, see instructions)

7. Contract/Grant No.

NATIONAL BUREAU OF STANDARDS

DEPARTMENT OF COMMERCE

WASHINGTON, D.C. 20234

\section{SPONSORING ORGANIZATION NAME AND COMPLETE ADDRESS (Street, City, Stote, ZIP)}

Federal Aviation Administration

Technical Center

Atlantic City, N.J. 08405

10. SUPPLEMENTARY NOTES

Document describes a computer program; SF-185, FIPS Software Summary, is attached.

11. ABSTRACT (A 200-word or less factual summary of most significant information. If document includes a significant bibliography or literature survey, mention it here) An attempt is made to develop mathematical predictions for various aspects of the dynamics of post-crash aircraft fires. The basis of the analysis is the experimental simulation scenario under study by the FAA. The effects of wind are considered as well as the effect of interior and exterior fires. Suggestions are presented for estimating cabin door flow rates from measured temperatures.

12. KEY WORDS (Six to twelve entries: alphabetical order: capitalize only proper names; and separate key words by semicolons) Aircraft compartments; aircraft fires; flow rates; mathematical models; wind effects.

13. AVAILABILITY

[X] Unlimited

For Official Distribution. Do Not Release to NTIS

Order From Superintendent of Documents, U.S. Government Printing Office, Washington, D.C. 20402.
14. NO. OF

PRINTED PAGES

25

15. Price

$\$ 6.00$

X. Order From National Technical Information Service (NTIS), Springfield, VA. 22161 

